\title{
TEMÁTICAS METODOLÓGICAS NO ENSINO DE MATEMÁTICA NA EDUCAÇÃO INFANTIL: UMA EXPERIÊNCIA DE FORMAÇÃO CONTINUADA NO MUNICÍPIO DE MATUPÁ, MATO GROSSO
}

\author{
METHODOLOGICAL THEMES IN MATHEMATICS TEACHING DURING CHILD EDUCATION: \\ A CONTINUING EDUCATION EXPERIENCE IN THE MUNICIPALITY OF MATUPÁ, MATO GROSSO
}

ANA MARIA DE JESUS MOURA ${ }^{1}$

\section{RESUMO}

Este artigo apresenta um recorte de uma dissertação de Mestrado defendida no Programa de Pós-graduação Stricto Sensu em Ensino de Ciências e Matemática da Universidade do Estado do Mato Grosso (PPGECM/Unemat). 0 objetivo foi discutir sobre a experiência de formação continuada no ensino de Matemática para professores da Educação Infantil em Matupá, estado do Mato Grosso. Assim, perguntamos como a formação continuada pode contribuir para a prática pedagógica na Educação Infantil, especificamente para o ensino de Matemática. 0 estudo seguiu uma abordagem qualitativa, nos moldes da pesquisa-ação discutida por Thiollent (2005), e adotou a perspectiva da análise interpretativa. Utilizou-se o recurso a questionários semiestruturados, com questões fechadas e abertas, registro de observação dos encontros formativos e relatórios de contribuição dos professores. A partir das análises, foi possível inferir que se faz necessário propiciar momentos de estudos e reflexões que possibilitem aos professores da Educação Infantil a compreensão acerca da importância de atividades desafiadoras.

Palavras-chave: Formação continuada de professores. Matemática. Prática pedagógica. Educação Infantil.

\section{ABSTRACT}

This paper presents an excerpt of a master's thesis presented at the "Programa de Pós-graduação Stricto Sensu em Ensino de Ciências e Matemática" of the State University of Mato Grosso (PPGECM/Unemat), in Brazil. The objective was to discuss the experience of continuing education in mathematics teaching for preschool teachers in Matupá, state of Mato Grosso. Therefore, we inquired how continuing education can contribute to the pedagogical practice in early childhood education, specifically to the teaching of Mathematics. The study adopted a qualitative approach, according to the procedures of the action research discussed by Thiollent (2005), and followed the perspective of interpretative analysis. We used semi-structured questionnaires, observation records of the formative meetings and the reports of the participating teachers. From the analyses, it was possible to infer that it is necessary to enable studies and reflections that will allow preschool teachers to understand the importance of challenging activities.

Keywords: Continuing teacher training. Mathematics. Pedagogical practice. Child education.

\footnotetext{
1 Licenciada em Pedagogia pela Universidade do Estado de Mato Grosso (2004), especialista em Psicopedagogia Clínica e Institucional pela Faculdade Internacional de Curitiba (2006). Complementação em Educação Infantil pela Faculdade Educacional da Lapa (2018). Mestra em Ensino de Ciências e Matemática pelo Programa de Pós-graduação Stricto Sensu em Ensino de Ciências e Matemática (PPGECM/Unemat), campus de Barra do Bugres, Mato Grosso, Brasil.(2020). ORCID: https://orcid.org/0000-0002-3656-4989
} 


\section{INTRODUÇÃO}

A formação continuada de professores é uma ação voltada para o aperfeiçoamento da prática docente e do conhecimento profissional. 0 objetivo principal dessa ação é aprimorar a prática docente em seu espaço de trabalho, refletindo sobre ela. Isso requer uma atenção e um planejamento consistente no exercício da realização pedagógica, que deve estar alicerçada em uma interação entre a teoria e a prática. 0 olhar para a atuação docente faz-nos refletir sobre a aprendizagem da Matemática - não apenas sobre as atividades de sala de aula, mas também sobre tempos e espaços na escola e fora dela.

A propósito da formação continuada, Nóvoa $^{2}$ (2013) defende que a boa formação de professor não passa apenas pela prática, pois "a prática por si só, não forma. 0 que forma é a reflexão sobre a experiência e a prática". Nessa mesma perspectiva, 0 autor português (1995, p. 25) aponta que "a formação não é um acúmulo de conhecimentos ou mesmo de técnicas, e sim de um trabalho reflexivo e crítico sobre a prática e de (re)construção permanente de uma identidade pessoal". Seguindo essa linha argumentativa, defendemos que a formação deve estimular o crescimento pessoal e profissional de cada educador.

No caso desta investigação, cujo foco foi a formação continuada realizada em uma escola municipal do estado do Mato Grosso, as ações formativas do corpo docente proporcionaram elementos significativos para a definição dos aspectos centrais da pesquisa. Sendo assim, a partir das experiências de aprendizagens dos profissionais da Educação, estabelecemos os seguintes objetivos específicos: contribuir com uma experiência de formação continuada no ensino de Matemática para professores da Educação Infantil de quatro e cinco anos no município de Matupá; refletir com os professores da escola pesquisada sobre os desafios que eles enfrentam na sala de aula em relação ao ensino da Matemática na Educação Infantil; e identificar quais as contribuições que esta formação continuada pôde proporcionar aos docentes.

Este artigo apresenta um recorte de uma dissertação de Mestrado defendida no Programa de Pós-graduação Stricto Sensu em Ensino de Ciências e Matemática da Universidade do Estado do Mato Grosso (PPGECM/Unemat). Tal pesquisa, por sua vez, surgiu a partir da experiência de uma das autoras como professora da Educação Infantil. Nessa trajetória profissional, foi possível perceber a necessidade da formação continuada na área do ensino da Matemática, especificamente no contexto educativo da Pré-Escola. Defendemos, então, que a formação de professores da Educação Infantil proporcione a esses profissionais a oportunidade de construir a própria prática, possibilitando, ainda, uma perspectiva reflexiva por meio de estudos e experiências construtivas relacionadas ao ambiente escolar da Educação Infantil. Neste contexto, o que se propôs nesta pesquisa foi uma contribuição para 0 ensino de Matemática e para a formação continuada de professores pedagogos no referido município mato-grossense.

Para isso, apoiamo-nos, principalmente, nos estudos de Nóvoa (1991; 1992; 1995; 2002; 2013), Freire (1991; 2002), Libâneo (1998) e Perrenoud (2010). Em relação aos saberes da prática docente, Freire (2002, p. 32) afirma que "todo educador é um pesquisador, ou deveria ser". Libâneo (2001) defende a importância da formação continuada no contexto escolar. Perrenoud (2000), por sua vez, aborda as competências necessárias para a formação contínua. Assim, partindo desses pressupostos, chegamos à seguinte pergunta condutora desta pesquisa: como

2 António Nóvoa (2013) foi convidado de honra no 4. ${ }^{\circ}$ Encontro Nacional das Licenciaturas (Enalic, 2013), evento que ocorreu em Uberaba, Minas Gerais, no campus da Universidade Federal do Triângulo Mineiro. 
a formação continuada pode contribuir para a prática pedagógica do professor da Educação Infantil, no que se refere ao ensino de Matemática?

Diante desta perspectiva, a realização desta pesquisa visou contribuir para uma compreensão do papel do professor na Educação Infantil no processo educativo e, em especial, da formação continuada no ensino da Matemática. É de nosso entendimento que essa etapa da Educação Pré-Escolar é de suma importância para 0 desenvolvimento educativo da criança e também para o conhecimento e 0 aprimoramento da prática pedagógica do professor.

\section{CONTEXTO TEÓRICO DA PESQUISA}

Nesta seção, apresentamos os referenciais teóricos utilizados para fundamentar esta pesquisa no que diz sobre o ensino da Matemática da Educação Infantil, a qual está ligada ao contexto social da criança e seu cotidiano, como também, estabelecer uma relação da formação continuada as práticas pedagógicas do professor.

\section{0 ensino da Matemática na Educação Infantil}

0 ensino da Matemática na Educação Infantil é de extrema importância para o desenvolvimento da criança, pois o mundo que a rodeia apresenta, de variadas formas, experiências matemáticas em sua vida. De fato, esta disciplina está presente em muitas das atividades que as crianças realizam, e 0 espaço escolar tem um vínculo importante nesse momento da formação humana, auxiliando a internalizar informações para que os conhecimentos necessários venham a ser usados nas várias situações que encontramos no dia a dia. Atualmente, verifica-se cada vez mais a necessidade de uma reflexão sobre os conhecimentos e práticas relativas à Educação Matemática na infância e no contexto do fazer profissional de professores que atuam na Educação Infantil. Por isso, é desafiador desenvolver práticas pedagógicas que possibilitem à criança compreender, de diferentes formas, 0 universo em que vive.

A Educação Infantil, hoje, é definida como a primeira etapa da Educação Básica na Lei de Diretrizes e Bases da Educação Nacional (LDB) (Lei n. ${ }^{0}$ 9394/1996). Conforme a Lei n. ${ }^{0}$ 12.796/2013, o atendimento a crianças de zero aos cinco anos, que tem por finalidade o desenvolvimento integral do público infantil em seus aspectos físicos, psicológicos e sociais, completando a ação da família, deve ser oferecida em creches e Pré-Escolas. Assim, "é dever do Estado garantir a oferta de Educação pública, gratuita e de qualidade, sem requisito de seleção" (BRASIL, 2010, p. 12)

A história das instituições da Educação Infantil é marcada pela luta para que os direitos da criança fossem assegurados por lei. Somente a partir da LDB (1996) é que se iniciou um processo de institucionalização educacional de crianças de zero aos seis anos no contexto educacional. Essa trajetória histórica é marcada por diferentes concepções de criança, infância e Educação, constituindo um período de pesquisas para a fundamentação teórica de educadores e pensadores renomados, tais como Maria Montessori, Froebel, Pestalozzi, Rousseau e Frinet, entre outros que deixaram uma marca no pensar sobre a Educação Infantil. Essas diferentes concepções de aprendizagem têm permeado 0 espaço educacional infantil, lançando discussões sobre como a criança aprende Matemática, levando em consideração os conhecimentos trazidos por ela no seu repertório cultural. Nesta área, há também uma necessidade de maior reflexão, principalmente sobre os conhecimentos e as práticas referentes ao ensino da Matemática no fazer pedagógico dos professores que atuam neste universo infantil. Nesse sentido, Smole, Diniz e Cândido (2000) afirmam que: 
As preocupações com o ensino da Matemática de qualidade desde a Educação Infantil são cada vez mais frequentes, e são inúmeros os estudos que indicam caminhos para fazer com que 0 aluno dessa faixa etária escolar tenha oportunidade de iniciar de modo adequado seus primeiros contatos com a disciplina. (SMOLE; DINIZ; CÂNDID0, 2000, p. 09).

Para essas autoras, o ensino da Matemática encontra-se inter-relacionado às demais áreas do saber, pois a Matemática não está isolada. Elas complementam:

Um dos maiores motivos para o estudo da matemática na escola é desenvolver a habilidade de resolver problema. Essa habilidade é importante não apenas para a aprendizagem matemática para a criança, mas também para o desenvolvimento de suas potencialidades em termos de inteligências e cognição. (SMOLE, DINIZ, CÂNDID0, 2000, p. 13).

Nesse sentido, Smole, Diniz e Cândido (2000) consideram que a Matemática está ligada ao contexto social da criança e aos saberes necessários do cotidiano. Dessa forma, a base matemática construída historicamente pelos homens há milhares de anos é marcada pelo seu dia a dia e pela exploração da linguagem matemática em um sujeito que organiza, cria, recria, pensa, brinca e aprende.

Sabemos que, independentemente da escola, as crianças constroem uma diversidade de conhecimentos nas atividades familiares ou mesmo nas situações vividas, favorecendo, assim, a elaboração de conhecimentos através de números, espaço, formas e medidas. Elas usam o controle remoto de TV, que traz números ou mesmo noções espaciais de em cima e embaixo, fazem compras, organizam brinquedos, sobem e descem algum obstáculo, observam contagens etc. Estas atividades Ihes proporcionam uma interação com o outro, favorecendo o conhecimento matemático nas mais diferentes formas de aprendizagem. Para as autoras (2000), as reflexões em relação aos processos de ensino e aprendizagem nesta etapa de escolaridade devem ser centradas em como e por que as crianças aprendem Matemática.

Percorrendo a história da Matemática, caracterizando-a como uma ciência, é possível entender que ela surgiu para dar respostas às necessidades do ser humano, pois essa disciplina está ligada diretamente à vida e às suas relações com o contexto em que vivemos e às mais variadas formas de convívio, tais como contar, calcular, organizar, ler, escrever, medir e entender as formas presentes no nosso cotidiano. Segundo Smole (2014), na Educação Infantil, a aprendizagem matemática se dá a partir da curiosidade e do entusiasmo das crianças e cresce em função do tipo de experiências vivenciadas nas aulas. 0 professor deve, portanto, ter em mente que, dessa forma, a criança pode tomar decisões agindo como produtora de conhecimento, contribuindo para uma formação cidadã. Smole, Diniz e Cândido (2000) afirmam que:

Ouvir, falar, ler, escrever, desenhar, são competências básicas para que os alunos aprendam conceitos em qualquer tempo e servem tanto para leva-los a interagir uns com os outros quanto para que desenvolvam uma melhor compreensão das noções envolvidas em uma dada atividade, pois qualquer meio que sirva para registrar ou transmitir informação incentiva a capacidade de compreensão e de análise sobre 0 que está realizando. (SMOLE, DINIZ E CÂNDIDO, 2000, p. 25). 
Quando pensamos no ensino da Matemática na Educação Infantil, direcionamos um olhar em especial ao professor, sujeito que julgamos importante nesse processo de investigação e apropriação do conhecimento. Entendemos que, nesse processo do ensino, devem-se respeitar as especificidades da criança na Educação Infantil. Nesse sentido, Tancredi (2004) afirma:

Ao ensinar Matemática na Educação Infantil, espera-se que essa não seja uma tarefa com hora marcada - agora é hora de aprender Matemática - mas que em tudo as crianças façam para desenvolver-se e adquirir competências e habilidades os conceitos matemáticos estejam sendo explorados. Isso exige dos professores planejamento minucioso do ensino e um conhecimento bastante grande dos assuntos matemáticos a serem apresentados, discutidos, sistematizados. (TANCREDI, 2004, p. 49-50).

Desse modo, uma forma privilegiada de apresentar o conhecimento matemático na Educação Infantil é a partir do brincar. De fato, a "participação ativa da criança e a natureza lúdica e prazerosa inerentes a diferentes tipos de jogos tem servido de argumento para fortalecer essa concepção, segundo a qual aprende-se Matemática brincando" (BRASIL, 1998, p. 211). Diante dessa reflexão, é importante perguntar: que Matemática professores e crianças precisam saber?

Buscamos responder a essa pergunta consultando o Referencial Curricular para a Educação Infantil (RCNEI) (BRASIL, 1998). Tal documento recomenda que a disciplina seja abordada em três blocos de conteúdo, a saber: números e sistema de numeração; grandezas e medidas; e espaço e forma. Ainda assim, há inúmeros questionamentos dos professores em relação ao ensino da Matemática na Educação Infantil. Por exemplo, os professores da referida pesuisa se indagam da incerteza sobre quais conhecimentos matemáticos deverão ser ensinados na Pré-Escola, para crianças de $4 \mathrm{e}$ 5 anos de idade é bastante frequente.

Conforme já adiantado, a importância do professor para a mediação do conhecimento é central. É preciso que se reconheça o seu importante papel no ensino e na aprendizagem, principalmente na qualidade de professor da Educação Infantil, e buscar meios para permitir uma melhor forma de condução do ensino da Matemática no contexto escolar. Nesse sentido, o RCNEI (BRASIL, 1998, p. 207) afirma que "a instituição de Educação Infantil pode ajudar as crianças a organizarem melhor as suas informações e estratégias, bem como proporcionar condições de novos caminhos matemáticos". No contexto da Educação Infantil, devemos considerar a importância dos conhecimentos matemáticos na construção da identidade da criança.

A Matemática está presente em diversas atividades realizadas pelas crianças, incluindo no ato de brincar; sendo assim, o brincar também permite ao professor conhecer a criança e as suas necessidades. De acordo com o RCNEl (1998), no ensino da Matemática, no cotidiano das instituições de Educação Infantil, há um grande equívoco ou mesmo uma contradição ao se pedir que a criança aprenda por meio da memorização e da repetição: a criança decora e não aprende realmente a lógica por trás das coisas. Segundo o RCNEI,

Propõe-se exercícios de escrita dos algarismos em situações como: passar o lápis sobre numerais pontilhados, colagem de bolinhas de papel crepom sobre os numerais, cópias repetidas de um mesmo numeral, escrita repetida da sucessão numérica. Ao mesmo tempo, é comum enfeitar os algarismos, grafando-os com figuras de bichos ou dando-Ihes um aspecto humano, com olhos, bocas e cabelos, ou ainda promovendo associação entre os algarismo e desenhos, por exemplo, o número 
2 associado a dois patinhos. Acredita-se que, dessa forma, a criança estará construindo 0 conceito de número. (BRASIL, 1998, p. 209).

Perante tal realidade referida pelo documento, os estudos sobre o desenvolvimento infantil e as pesquisas realizadas no próprio contexto da Educação Matemática permitem questionar essa concepção de aprendizagem nas instituições de Educação Infantil. Trata-se de tensionar, no âmbito escolar da Educação Infantil e, principalmente, nas etapas da Pré-Escola, a ideia de que o conhecimento matemático deva ser sempre apresentado com base em métodos tradicionais para a escolarização no Ensino Fundamental.

Para o RCNEI (BRASIL, 1998, p. 213), as noções matemáticas construídas pelas crianças dão-se por meio das experiências promovidas pelas "interações com o meio, pelo intercâmbio com outras pessoas que possuem interesses, conhecimentos e necessidades que podem ser compartiIhados". Ainda segundo o documento:

As crianças têm e podem ter várias experiências com 0 universo matemático e outros que thes permitem fazer descobertas, tecer relações, organizar o pensamento, o raciocínio lógico, situar-se e localizar-se espacialmente. Configura-se desse modo um quadro inicial de referências lógico matemáticas que requerem outras, que podem ser ampliadas. São manifestações de competências, de aprendizagem advindas de processos informais, da relação individual e cooperativa da criança em diversos ambientes e situações de diferentes naturezas, sobre as quais não se tem planejamento e controle. (BRASIL, 1998, p. 213).

Na perspectiva desse documento, a continuidade da aprendizagem matemática não dispensa a intencionalidade e o planejamento, bem como as atividades de formular, perguntar, suscitar desafios e incentivar a verbalizar - todas são atitudes indispensáveis para o conhecimento matemático em particular. Como auxílio para o professor no ensino de Matemática, Lorenzato (2011) destaca três campos básicos: 0 espacial, o numérico e 0 das medidas. 0 primeiro irá fornecer as bases para o estudo da geometria; 0 segundo, para 0 estudo da aritmética; e o terceiro integrará a geometria com a aritmética. Segundo 0 autor, esse trabalho deve envolver as noções espaciais, tais como: grande/pequeno, perto/longe, dentro/fora, começo/meio/fim, na frente/atrás/ao lado, ganhar/perder, aumentar/diminuir.

Essas noções devem ser introduzidas ou revisadas verbalmente e por meio de diferentes situações, materiais manipuláveis, desenhos, histórias ou pessoas. Essa diversidade de modo de tratamento de cada noção é que facilitará a percepção de significados de cada uma delas. Como o tratamento está no plano verbal, torna-se favorável a utilização de indagações, tais como: Como ele é? Onde ele está? 0 que está acontecendo? Onde aconteceu isto? Como eles são diferentes? Qual é o maior? Para onde ele foi? etc. Cujas respostas recaem diferentemente nas noções mencionadas anteriormente. (LORENZAT0, 2011, p. 24).

Para Lorenzato (2011), não importa a sequência das noções que devem ser trabalhadas. 0 importante é estabelecer uma relação direta com os conceitos físicos matemáticos, tais como: lugar, número, quantidade, posição, direção, volume, capacidade etc. A criança precisa vivenciar a 
Matemática para que a aprendizagem aconteça na prática, por meio da ação direta da criança com 0 meio onde está inserida.

De modo a que todas as noções matemáticas sejam trabalhadas e compreendidas pelas crianças, Lorenzato (2011, p. 25) ressalta que o professor deve conhecer os sete processos mentais básicos para a aprendizagem da disciplina em questão, que são: (1) correspondência: ato de estabelecer a relação um a um; (2) comparação: ato de estabelecer diferenças e semelhanças; (3) classificação: ato de separar por categorias de acordo com semelhanças ou diferenças; (4) sequenciação: ato de fazer suceder a cada elemento um outro sem considerar a ordem entre eles; (5) seriação: ato de dar ordem a uma sequência segundo um dado critério; (6) conservação: ato de perceber que a quantidade não depende da arrumação, forma ou posição; (7) inclusão: ato de fazer abranger um conjunto por outro. Nesses processos, é preciso trabalhar aprendizagens com o mesmo assunto de maneiras variadas, "pois é justamente essa diversidade de atividades, experiências e contextos, a respeito de um mesmo conceito, que favorece a formação do conceito que está sendo construído pela criança" (LORENZATO, 2011, p. 29).

Lorenzato (2006, p. 30) afirma ainda que essas habilidades, na Educação Infantil, interpõem-se e integram-se, "num vai e vem contínuo e pleno de inter-relacionamento e, assim, um vai esclarecendo e apoiando o outro na elaboração dos conceitos". Segundo o RCNEI (1998), como já citado anteriormente, é necessário saber e trabalhar três blocos de conteúdos na Educação Infantil (números e sistema de numeração, grandezas e medidas e espaço e forma). Essa organização por blocos, conforme apresenta o Referencial, visa a oferecer visibilidade às especificidades dos conhecimentos matemáticos a serem trabalhados (BRASIL, 1998, p. 219). Compreender os conceitos matemáticos na Educação Infantil é fundamental para a criança nessa fase de aprendizagem, pois "decorrem do contato e utilização desses conhecimentos em problemas cotidianos, no ambiente familiar, em brincadeiras, nas informações que thes chegam por meio de comunicação" (BRASIL,1998, p. 220). 0 professor pode propor situações e procedimentos diferenciados, ao dispor de materiais que possam ser explorados pelas crianças, e manuseá-los a fim de que as crianças se deem conta de que podem progredir em seus conhecimentos matemáticos. Isso poderá atender às necessidades da própria criança de construir seus conhecimentos nas mais variadas formas no universo matemático, com experiências que lhes permitam fazer descobertas.

A implantação da Base Nacional Comum Curricular (BNCC) em 2018, impactará diretamente nos conhecimentos e nas práticas pedagógicas em sala de aula em todos os níveis da Educação Básica. Para atender às mudanças curriculares e às diretrizes que direcionam 0 documento, 0 Ministério da Educação (MEC), investiu plenamente na formação dos professores da Educação Básica, oportunizando a formação continuada para os que já atuam nesse nível de ensino e estimulando as mudanças para os cursos de Licenciatura (BRASIL, 2017).

Para a proposta da Educação Infantil, a BNCC está alinhada às Diretrizes Curriculares Nacionais da Educação Infantil (DCNEI), de 2010, cuja função é normatizar o funcionamento da Educação Infantil, orientando as políticas públicas da área no que diz respeito à elaboração, ao planejamento, à execução e à avaliação de propostas pedagógicas. Em seu currículo, a Educação Infantil se estrutura por campos de experiências, os quais são definidos seus objetivos de aprendizagem e desenvolvimento. Para o professor, as mudanças representam um grande desafio, pois haverá ajustes necessários na metodologia, no planejamento e na prática pedagógica.

Para Nóvoa (1992), sem a correspondente formação de professores, não há ensino de qualidade, reforma educativa ou renovação pedagógica. Considerando que uma das dificuldades dos 
profissionais da Educação Infantil é compreender os conteúdos a serem trabalhados em cada campo de experiências e relacioná-Ios às habilidades para cada faixa etária, a BNCC representa um desafio para os professores no atual momento de implementação. Esse documento passa a servir de referência obrigatória para a construção dos currículos nas escolas nos seus estados e municípios. Sendo assim, a discussão e a incorporação desse documento na Educação Infantil são importantes para 0 profissional em sala de aula.

\section{Formação continuada de professores da Educação Infantil}

Pensar na formação continuada e nos processos de ensino e aprendizagem é pensar em fortalecer 0 objetivo de estabelecer uma relação entre a formação continuada e a prática pedagógica. Algumas reflexões acerca da formação continuada ou contínua do professor em sala de aula/serviço constituem uma necessidade para garantir a qualidade de ensino e a melhoria do trabalho pedagógico da escola.

Embora os debates e os estudos sobre formação continuada não sejam recentes, ainda existem lacunas a serem preenchidas a respeito de construir ações permanentes, metas a serem alcançadas e intervenções pedagógicas nesse domínio, promovendo, assim, a melhoria no ensino e na aprendizagem no contexto escolar. Nóvoa (2002) afirma que 0 aprender contínuo é essencial para o contexto educacional, concentrando-se em dois pilares: na própria pessoa, como agente; e na escola, como lugar de crescimento profissional permanente.

Conforme já adiantado, os estudos sobre a formação continuada têm envolvido um número considerável e crescente de autores. 0 mesmo acontece quando 0 foco é dirigido à formação continuada que acontece no interior da escola, na perspectiva dos conhecimentos docentes e da prática pedagógica, defendida por autores como Nóvoa (1995), Freire (1991), Perrenoud (2000), Imbernón (2010) e outros. Paulo Freire (1991, p. 58) defendeu que "ninguém nasce educador ou marcado para ser educador. A gente se faz educador, a gente se forma, como educador, permanentemente, na prática e na reflexão da prática". Na formação continuada, os desafios são constantes e centrados no espaço escolar, nas situações vivenciadas nesse contexto. 0 objetivo é buscar soluções e estratégias que venham ao encontro e ao auxílio dos desafios pedagógicos.

Ao mencionar a importância dessa formação, Kramer (2002) destaca a formação docente do professor de Educação Infantil, enfatizando as especificidades da infância, fase essencial na vida do ser humano. "As profissionais [...] que atuam com crianças precisam assumir a reflexão sobre a prática, o estudo crítico das teorias que ajudam a compreender as práticas, criando estratégias de ação, rechaçando receitas ou manuais" (KRAMER, 2002, p. 129). Nessa mesma direção argumentativa, Nóvoa (1992) lembra que a escola é um espaço de novas formas de trabalho - um espaço de troca de conhecimentos, experimentação e inovação.

Ao se tratar da formação docente no campo da Educação Infantil, é preciso, em primeiro lugar, situar a sua posição no cenário brasileiro, mencionando os principais fatos que marcaram a sua constituição como modalidade de ensino. Como já mencionado anteriormente, a Educação Infantil está vinculada a um passado de práticas predominantemente assistencialistas e compensatórias, firmadas como "direitos da criança" a partir da Constituição de 1988. A partir da década de 1990, esse nível de Educação foi ganhando cada vez mais destaque, tendo como marco principal o seu reconhecimento como modalidade de ensino, contemplada como "primeira etapa da Educação Básica", na LDB de 1996.

A partir desse marco, cresceram ainda mais discussões acerca das necessidades formativas específicas do profissional da Educação Básica, principalmente dos profissionais que atuam com 
as crianças pequenas, desde a formação inicial oferecida em nível de graduação nos cursos de Pedagogia até a oferta de formação continuada como prática a ser garantida pelas redes de ensino. A LDB dispõe que "a União, o Distrito Federal, os Estados e os Municípios, em regime de colaboração, deverão promover a formação inicial, a continuada e a capacitação dos profissionais de magistério" (BRASIL, 1996). 0 mesmo está também contemplado no Referencial para a Formação de Professores, desta forma:

[...] necessidade intrínseca para os profissionais da Educação escolar, e se faz parte de um processo permanente de desenvolvimento profissional que deve ser assegurado a todos. A formação continuada deve propiciar atualizações, aprofundamento das temáticas educacionais e apoiar-se numa reflexão sobre a prática educativa, promovendo um processo constante de auto avaliação que oriente a construção contínua de competências profissionais. (BRASIL, 2002, p. 70).

Portanto, a oferta de formação continuada está garantida aos profissionais da Educação Básica na legislação, e está contemplada também no Referencial (BRASIL, 2002) e em outros documentos nacionais. Esses dispositivos mostram a importância que este tema tem para os profissionais de Educação Infantil nos dias atuais. Dada a complexidade deste tema, muitos autores se referem à formação continuada dos profissionais de Educação Infantil como um desafio. Kramer afirma (2006, s/p):

A formação de profissionais da Educação Infantil - professores e gestores - é desafio que exige a ação conjunta das instâncias municipais, estaduais e federal. Esse desafio tem muitas facetas, necessidades e possibilidades, e atuação, tanto na formação continuada (em serviço ou em exercício, como se tem denominado a formação daqueles que já atuam como professores) quanto na formação inicial no Ensino Médio ou superior.

A formação do profissional que trabalha na Educação Infantil pode se refletir tanto na formação pessoal quanto na pedagógica, em sala de aula. Pensando na realidade do professor deste nível de ensino, é necessário que ele tenha uma formação adequada e de qualidade, o que the permita, em seu dia a dia de trabalho, abordar com segurança e propriedade elementos relacionados aos mais variados temas e às mais diversas linguagens. Com isso, ressaltamos a importância da formação continuada, e, a esse propósito, Nóvoa (1991) afirma:

A formação continuada deve estar articulada com desempenho profissional dos professores, tomando as escolas como lugares de referência. Trata-se de um objetivo que só adquire credibilidade se os programas de formação se estruturarem em torno de problemas e de projetos de ação e não em torno de conteúdos acadêmicos. (NÓVOA,1991, p. 30).

A formação de professores que atuam na Educação Infantil torna-se fundamental para os profissionais desta área, pois, de acordo com Nóvoa (1992):

A formação não se constrói por acumulação de cursos, de conhecimento ou de técnicas, mas sim através de um trabalho de reflexibilidade crítica sobre práticas 
e de (re)construção permanente de uma identidade pessoal. A formação vai e vem, avança e recua, construindo-se num processo de relações ao saber e ao conhecimento. (NÓVOA, 1992, p. 13).

É importante salientar que o professor reconheça a importância desse processo de formação e da sua continuidade, buscando sempre se qualificar com 0 objetivo de aprimorar sua prática pedagógica e profissional. Pensando na perspectiva abordada pelos autores citados, podemos nos perguntar: que tipo de formação continuada na escola esse profissional de Educação Infantil deveria receber?

A formação continuada de professores da Educação Infantil deve acompanhar as transformações pelas quais esse nível de ensino atravessa. No estado do Mato Grosso, o Documento Referencial Curricular (DRC/MT, 2018) orienta 0 trabalho da Educação Infantil a partir de diferentes campos de experiências. Nesse documento, são apresentadas as concepções orientadas à prática pedagógica do professor e à organização curricular por campos de experiências, os quais têm como eixos norteadores as interações e brincadeiras. Essas concepções resultam no entendimento de que, por meio do papel mediador do professor, os saberes e os conhecimentos se articulam na busca por alcançar não só determinados objetivos de aprendizagem, mas também o desenvolvimento e o delineamento da formação dos profissionais, de modo a promover o respeito à criança como cidadã de direitos (BRASIL, 2018). Nesse sentido, pensar em uma proposta pedagógica em uma instituição de Educação Infantil é articular as experiências vivenciadas pelas crianças a partir de seus saberes, de seus conhecimentos e de suas manifestações, respeitando as especificidades de cada faixa etária.

\section{CAMINHOS METODOLÓGICOS}

Preocupando-nos com o processo, com o significado e com o conhecimento, buscamos apreender as diversas perspectivas dos sujeitos participantes na pesquisa, partindo de pressupostos teóricos, conforme dispõem Minayo (2000) e Bogdan e Biklen (1994). Neste artigo, a pesquisa-ação foi a estratégia metodológica usada para estudar as ações dos participantes, com a intenção de poder intervir no decorrer do processo de uma ação transformadora. A pesquisa-ação, segundo Thiollent (2005, p. 16), "é um tipo de pesquisa social com base empírica concebida e realizada em estreita associação com ação ou resolução de um problema coletivo, no qual os pesquisadores e os participantes representativos da situação ou problema estão envolvidos". Essa abordagem de pesquisa está comprometida com a produção de conhecimento por meio da busca e da solução de problemas ou de melhorias em situações práticas de vida real.

Para a produção dos dados, foram utilizados questionários semiestruturados, com questões fechadas e abertas, respondidas pelos sujeitos da pesquisa - professoras da Educação Infantil da rede municipal de ensino do município de Matupá, no Mato Grosso. As perguntas que compuseram esse instrumento versaram sobre dados de identificação, situação profissional dos sujeitos participantes e tempo de atuação na Educação Infantil. Além disso, na formação continuada proposta, as professoras, ao final de cada encontro, produziram um relatório descritivo, que também se constituiu como um instrumento de produção de dados.

Adotou-se ainda uma análise interpretativa, com base nas ideias de Severino (2007), que nos ofereceu um roteiro para 0 estudo dos textos produzidos. Os diálogos das participantes na formação continuada proposta foram, assim, analisados segundo essa perspectiva. Para Severino (2007, p. 94), interpretar é "tomar uma posição própria a respeito das ideias enunciadas, é superar a estrita 
mensagem do texto, é ler nas entrelinhas, é forçar o autor a um diálogo, é explorar a faculdade das ideias expostas, é cotejá-las com outros, é dialogar com o autor".

Severino (2007) lista também os cinco processos básicos da análise, que são os seguintes: 1 - análise textual; 2 - análise temática; 3 - análise interpretativa; 4 - problematização; e 5 - síntese pessoal. Nas reflexões em nossos estudos, usamos a análise interpretativa, conforme já referido. Segundo Severino (2007) tal tipo de análise visa:

Aproximar e associar ideias do autor expressas na unidade com outras ideias relacionadas à mesma temática; exercer uma atitude crítica diante das posições do autor em termos de: a) Coerência interna da argumentação; b) validade dos argumentos empregados; c) originalidade do tratamento dado ao problema; d) profundidade de análise ao tema; e) alcance de suas conclusões e consequências; f) apreciação e juízo das ideias defendidas. (SEVERINO, 2007, p. 65).

Nesses termos, segundo o autor, o pesquisador irá proceder a uma interpretação do texto, inferindo e interpretando o que apreciou, tendo o cuidado para que essa análise de interpretação não seja influenciada por questionamentos e pensamentos enviesados.

\section{INSTRUMENTOS DE ANÁLISES DE DADOS}

Para compreendemos a importância da formação continuada na ação do profissional de Educação Infantil, buscamos, nas “Temáticas Metodológicas no Ensino de Matemática”, uma contribuição para as práticas pedagógicas dessa etapa de ensino. Tendo como eixo básico as relações entre teoria e prática, ensino e aprendizagem, conteúdo e pesquisa, o curso ministrado no âmbito desta pesquisa foi pautado por uma reflexão e por uma análise das práticas pedagógicas e da própria formação continuada na área da Matemática. Foram abordados diversos tópicos: Metodologias Ativas, Material Dourado, Cartoons, BNCC, Matemática e Literatura, Caixa da Matemática (Pnaic) e Psicomotricidade.

De modo a dar reconhecimento à importância dos conhecimentos adquiridos ao longo do curso de Mestrado do PPGECM/Unemat e a oportunizar aos profissionais de Educação Infantil da escola pesquisada uma formação continuada no ensino da Matemática, fizemos uma parceria com mestrandos e mestres desse programa. Dessa forma, definimos quais as temáticas abordadas e distribuímo-las em oito encontros com uma carga horária de 40 horas. 0 público-alvo definido para esses encontros foram 13 professoras da pré-escola que lidam com alunos na faixa etária de quatro e cinco anos.

0 curso foi voltado especificamente para 0 ensino da Matemática. 0 seu objetivo geral foi oportunizar uma formação continuada com enfoque no ensino dessa disciplina aos professores de Educação Infantil da rede pública de ensino do município de Matupá. Além disso, buscou-se refletir com esses professores sobre os desafios que se encontram na sala de aula, contribuindo, com as temáticas abordadas, para melhorar o trabalho docente.

Escolhemos pesquisar sobre 0 ensino da Matemática por estarmos cientes das dificuldades comumente associadas a essa área de conhecimento. Assim, procuramos escolher as temáticas abordadas considerando as reais necessidades pedagógicas das professoras participantes e as necessidades gerais do ensino de Matemática na prática. Aliás, foi com base nessa estratégia que se planejou toda a proposta de formação para este curso. Por meio de exploração das temáticas esco- 
Ihidas, foram mobilizadas atividades teóricas e práticas, com recurso a oficinas, rodas de conversa, momentos de socialização, musicalização e brincadeiras dirigidas. Ao todo, houve oito encontros temáticos, conduzidos de acordo com a programação mostrada no quadro 1.

Quadro 1 - Programação dos encontros de formação continuada.

\begin{tabular}{|c|c|c|c|}
\hline \multicolumn{4}{|c|}{ Curso: TEMÁTICAS METODOLÓGICAS NO ENSINO DE MATEMÁTICA NA EDUCAÇÃO INFANTIL } \\
\hline \multicolumn{2}{|c|}{ Local: Escola M. Mundo Encantada da Criança } & Ano: 2019 & $1 .^{\circ}$ e $2 .{ }^{\circ}$ semestres \\
\hline \multicolumn{4}{|c|}{ Público-alvo: Professores da Educação Infantil da rede municipal que atuam nas etapas de ensino dos 4 aos 5 anos de idade. } \\
\hline \multicolumn{4}{|c|}{ N. ${ }^{0}$ de participantes: 13 professoras } \\
\hline \multicolumn{4}{|c|}{ Carga horária: 40 horas } \\
\hline \multicolumn{4}{|c|}{$\begin{array}{l}\text { Responsável: Mestranda Ana Maria de Jesus Moura } \\
\text { Orientadora: Prof. Dra. Cláudia Landin Negreiros }\end{array}$} \\
\hline \multicolumn{4}{|c|}{ Encontros de formação continuada de professores na Educação Infantil } \\
\hline ENCONTROS & TíTULO & TEMAS ABORDADOS & PALESTRANTE \\
\hline $\begin{array}{l}1.0 \text { encontro } \\
13 / 4 / 2019\end{array}$ & Apresentação do Projeto & $\begin{array}{l}\text { Temáticas Metodológicas no Ensino de Matemática } \\
\text { na Educação Infantil: uma experiência de formação } \\
\text { continuada de professores em Matupá - MT. }\end{array}$ & $\begin{array}{l}\text { Mestranda } \\
\text { A. M. de J. M. } \\
\text { (PPGECM/Unemat) } \\
\end{array}$ \\
\hline $\begin{array}{l}2 .^{0} \text { encontro } \\
27 / 4 / 2019\end{array}$ & Metodologias Ativas & $\begin{array}{l}\text { Competências do professor dentro da BNCC, } \\
\text { Matemática na Educação Infantil. }\end{array}$ & $\begin{array}{l}\text { Mestrando } \\
\text { E. O. F } \\
\text { (PPGECM/Unemat) } \\
\end{array}$ \\
\hline $\begin{array}{l}3 .^{\circ} \text { encontro } \\
18 / 5 / 2019\end{array}$ & $\begin{array}{l}\text { Material Dourado para a } \\
\text { Educação Infantil }\end{array}$ & $\begin{array}{l}\text { História do Material Dourado e } \\
\text { Conceito matemáticos }\end{array}$ & $\begin{array}{l}\text { Mestranda } \\
\text { C. S. F. } \\
\text { (PPGECM/Unemat) }\end{array}$ \\
\hline $\begin{array}{l}4 .^{0} \text { encontro } \\
25 / 5 / 2019\end{array}$ & $\begin{array}{l}\text { Produzindo Cartoons na } \\
\text { Educação Infantil }\end{array}$ & $\begin{array}{l}\text { Tecnologias digitais, } \\
\text { Conceito básico e } \\
\text { Produção de Cartoons }\end{array}$ & $\begin{array}{l}\text { Mestrando } \\
\text { L. M. S. } \\
\text { (PPGECM/Unemat) }\end{array}$ \\
\hline $\begin{array}{l}5^{0} \text { encontro } \\
15 / 6 / 2019\end{array}$ & $\begin{array}{l}\text { Roda de Conversa sobre } \\
\text { a BNCC }\end{array}$ & $\begin{array}{l}\text { Marcos Legais e Construção da História dos } \\
\text { Documentos Brasileiros: BNCC e DRC - MT. }\end{array}$ & $\begin{array}{l}\text { Ma. G. M. } \\
\text { e D. E. B. } \\
\text { (Cefapro Sinop/MT) }\end{array}$ \\
\hline $\begin{array}{l}6 .^{\circ} \text { encontro } \\
06 / 7 / 2019\end{array}$ & $\begin{array}{l}\text { Matemática e Literatura } \\
\text { infantil }\end{array}$ & Oficina Temática & $\begin{array}{l}\text { Mestranda } \\
\text { A. M. J. M. } \\
\text { (PPGECM/Unemat) }\end{array}$ \\
\hline $\begin{array}{l}\text { 7. }{ }^{\circ} \text { encontro } \\
19 / 07 / 2019\end{array}$ & $\begin{array}{l}\text { Caixa da Matemática } \\
\text { (Pnaic) }\end{array}$ & $\begin{array}{l}\text { Oficina Temática: Construção da Caixa de Mate- } \\
\text { mática com jogos e brincadeiras }\end{array}$ & $\begin{array}{l}\text { Ma. V.P. } \\
\text { (PPGECM/Unemat) }\end{array}$ \\
\hline $\begin{array}{l}8 .^{\circ} \text { encontro } \\
21 / 09 / 2019\end{array}$ & Psicomotricidade & Definições e Benefícios & $\begin{array}{l}\text { Me. V. S. } 0 . \\
\text { (IFMT/Guarantã do Norte/MT) }\end{array}$ \\
\hline
\end{tabular}

Fonte: Elaborado pelas autoras (2019).

As temáticas do curso apresentadas no Quadro 1 contemplam as contribuições de teorias e práticas metodológicas voltadas para os professores da Pré-Escola participantes do curso. Ao final de cada encontro de formação, as participantes fizeram um relatório sobre a contribuição dessa formação para a sua prática pedagógica.

\section{RESULTADOS E DISCUSSÕES}

Com 0 intuito de dar respostas aos objetivos traçados nesta pesquisa, procedemos às primeiras interpretações dos encontros, tomando como base os referenciais teóricos e os dados coletados. 
Tais dados foram discutidos em três eixos: eixo 1: entrevista semiestruturada e caracterização das professoras participantes - trajetória acadêmica e profissional; eixo 2: concepção das professoras sobre 0 ensino da Matemática na Educação Infantil; eixo 3: registro de observação em diário de campo das formações continuadas com as professores da Educação Infantil e relatórios das professoras acerca dos encontros de formação.

Com base nesses três eixos, nos propusemos a refletir sobre os resultados em relação ao ensino da Matemática na Educação Infantil e identificar quais foram as contribuições que essa formação continuada pôde proporcionar às participantes. De modo a garantir o anonimato, atribuímos às professoras da pesquisa as nomenclaturas "P1", "P2", "P3" etc. Os professores participantes dessa pesquisa todas possuem graduação em Pedagógia e os gráficos a seguir apresentam dados relativos ao eixo 1, 0 da trajetória acadêmica e profissional das participantes.

Gráfico 2 - Formação acadêmica das professoras participantes.

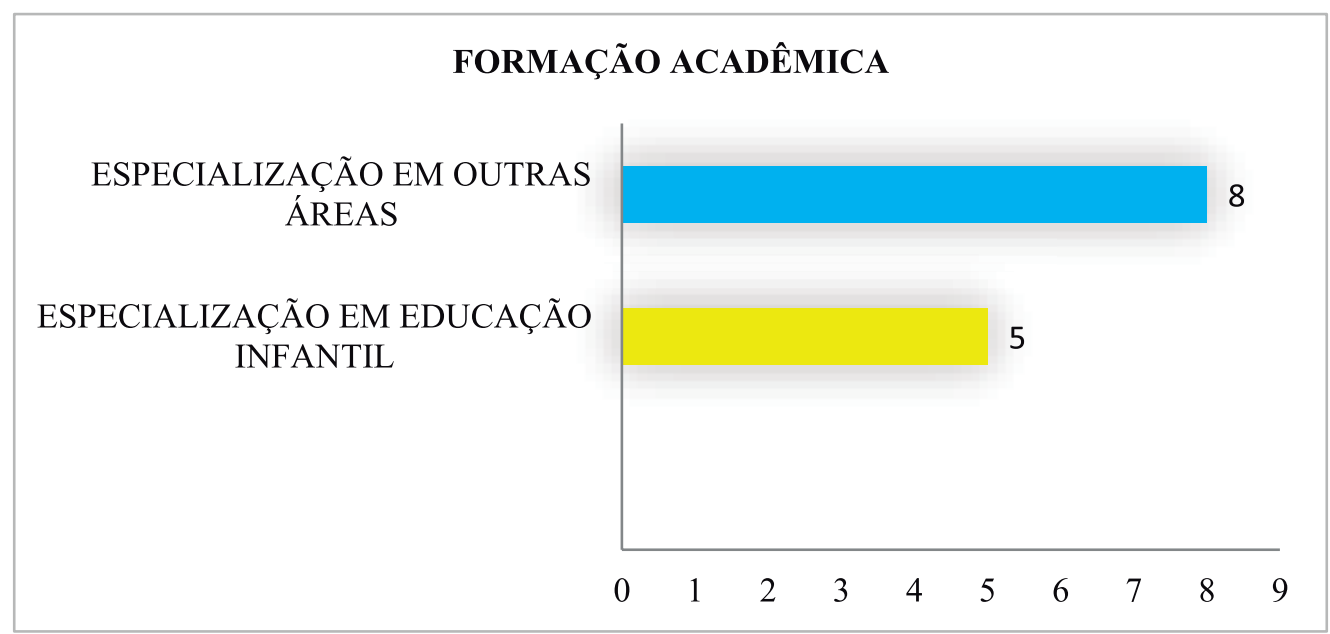

Fonte: Elaborado pelas autoras (2019).

Gráfico 3 - Tempo de experiência na Educação Infantil.

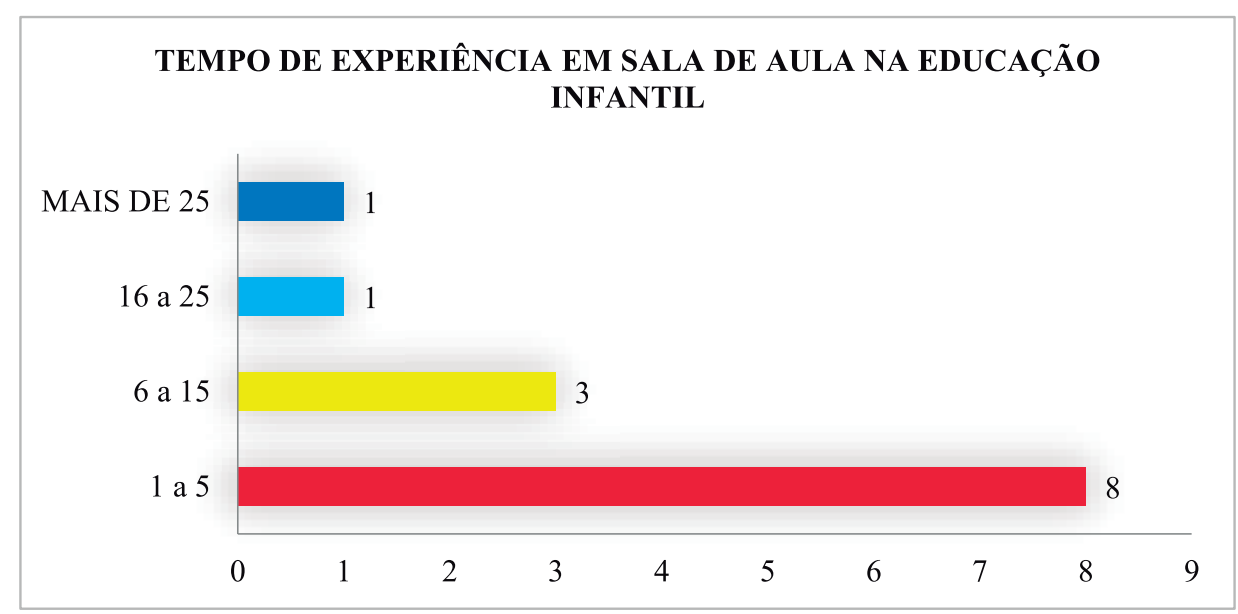

Fonte: Elaborado pelas autoras (2019). 
Gráfico 4 - Professores no exercício da docência.

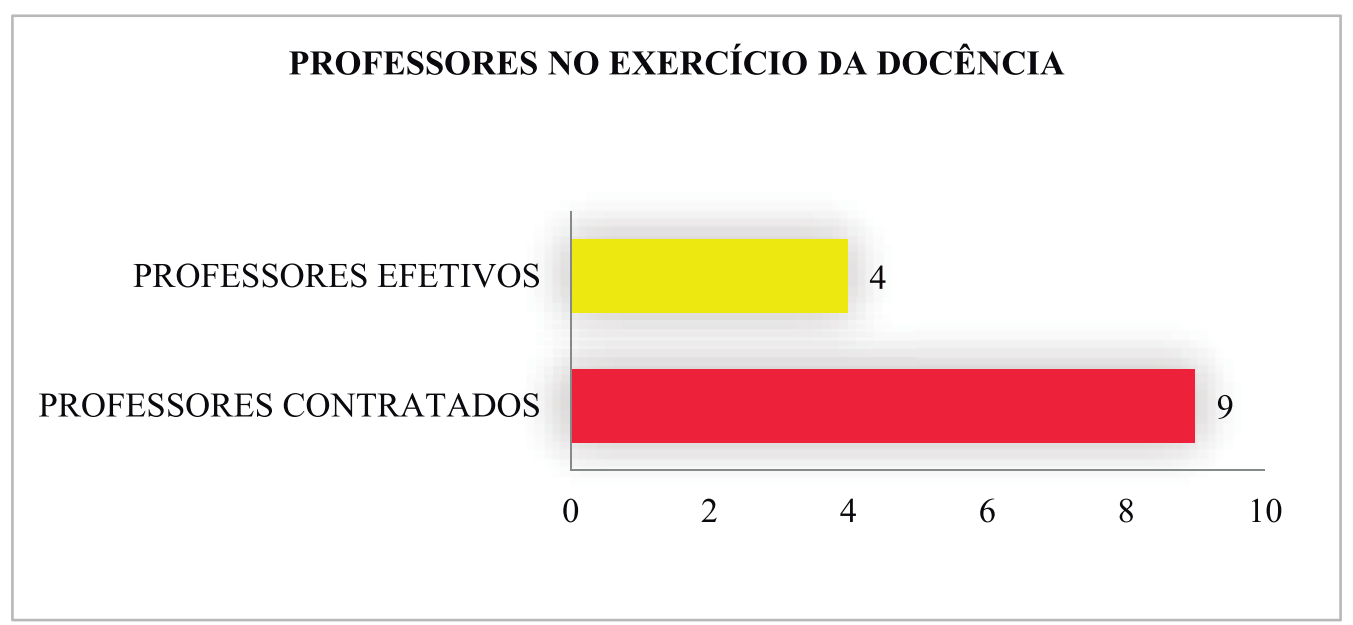

Fonte: Elaborado pelas autoras (2019).

Em seguida, apresentamos discussões relativas ao eixo 2, que versa sobre a concepção das professoras sobre o ensino da Matemática na Educação Infantil. As professoras apresentam uma concepção de Matemática que pode ser caracterizada como "realista", com foco no cotidiano. Uma das participantes, P1, afirmou: "Eu sei que a Matemática está presente em tudo", vinculando a disciplina ao ambiente e a situações da vivência dos sujeitos. É interessante notar que as professoras se referem à Matemática como "uma matéria" ou mesmo "uma disciplina". Na verdade, na Educação Infantil, não há momento de se ensinar Matemática, pois ela já está inserida no ambiente de aprendizagem, seja dentro de sala de aula ou fora dela. Isso se dá uma vez que, conforme afirma Lorenzato (2011, p. 1), "a exploração matemática pode ser um bom caminho para favorecer o desenvolvimento intelectual, social e emocional da criança".

Ao tentarem definir o que é a Matemática, as professoras destacam alguns conhecimentos sobre conteúdos matemáticos, tais como números, numerais, formas, espaços, grandezas e medidas. Para Lorenzato (2011, p. 1), "do ponto de vista do conteúdo matemático, a exploração matemática nada mais é do que uma primeira aproximação das crianças, intencionalmente e direcionada, ao mundo das formas e das quantidades". Baseado no que diz o autor, a professora afirma em suas palavras que é preciso entender a matemática para ensina-lá. P1 afirma, em sua escrita, o seguinte: "É a nossa base em toda atividade desenvolvida, usamos a Matemática, mas temos que entender a Matemática".

0 trabalho com as noções matemáticas na Educação Infantil é um espaço privilegiado para a apropriação da aprendizagem matemática. Nesse momento, acreditamos que certas noções são a base de construção de conhecimentos. Conforme o RCNEl, os conhecimentos são construídos pelas crianças por meio de experiências promovidas pelas "interações com 0 meio, pelo intercâmbio com outras pessoas que possuem interesses, conhecimentos e necessidades que podem ser compartilhados" (BRASIL, 1998, p. 213). De acordo com esse pensamento, buscamos, nas falas das professoras, 0 entendimento dessas noções básicas que são estimuladas e desenvolvidas na Educação Infantil.

Ao descreverem sobre quais noções matemáticas as crianças podem desenvolver na primeira infância, as professoras identificam alguns desses conceitos - é possível, assim, encontrar aproximações em suas falas. Porém, também se verifica uma confusão no entendimento de alguns conceitos 
nas falas de P2, P3 e P7, quando essas professoras atribuem noções matemáticas às formas geométricas. Na Educação Infantil, trabalha-se com as formas geométricas e estas não foram relacionadas, nas falas das participantes, a tópicos tais como: "Noções de lateralidade, formas geométricas, posições, noções de quantidade" (P2); "Noções das três operações(soma, divisão e subtração), formas geométricas, noções de espaço entre outras" (P3); "Trabalhar com símbolos, figuras geométricas e quantidades tudo na ludicidade" (P7).

Lorenzato (2011, p. 24) sugere realizar a exploração matemática a partir de dois pontos básicos: "o de aproveitar os conhecimentos e habilidades de que as crianças são portadoras e 0 de explorar os três campos matemáticos". 0 autor destaca ainda três campos a serem explorados: 0 espacial, 0 numérico e 0 das medidas. Além disso, para que traga uma probabilidade de sucesso, o trabalho em sala de aula deve ser conduzido a partir das seguintes noções matemáticas: grande/pequeno, mais/ menos, aberto/fechado, maior/menor, igual/diferente, em cima/embaixo, entre outras. Para isso, é importante ressaltar que essas noções devem ser claramente compreendidas pelo professor, que deve agir com segurança nas propostas das atividades. Lorenzato (2011) afirma que:

Se o professor não trabalhar com as crianças esses processos, elas terão grande dificuldades para aprender números e contagem, entre outras noções. Sem o domínio desses processos, as crianças poderão até dar respostas corretas, segundo a expectativa e a lógica do adulto, mas, certamente, sem significado ou compreensão para elas. (LORENZATO, 2011, p. 25).

É importante que os professores compreendam esses processos e que estes também sejam compreendidos pelas crianças. Conforme 0 autor salienta, "essas noções devem ser introduzidas ou revisadas verbalmente e por meio de diferentes situações, materiais, desenhos, histórias ou pessoas" (LORENZATO, 2011, p. 24). Tendo em vista que a educação é um processo contínuo e que 0 professor faz parte de tal processo, é preciso investir na formação docente. De fato, "o professor é um dos profissionais que mais necessita se manter atualizado, alinhado à tarefa de ensinar a tarefa de estudar" (MELLO, 1999, p. 26).

P2 afirma que "O professor é um mediador, estimulador dos conhecimentos que vai nortear [0 aluno] de forma acadêmica". Assim, ela acredita que o papel do professor é o de um mediador, ou seja, ele precisa conhecer o seu aluno, precisa saber o que ensinar, respeitando as diferenças e valorizando as experiências infantis. Libâneo (1998) afirma que:

0 professor medeia a relação ativa do aluno com a matéria, inclusive com os conteúdos próprios de sua disciplina, mas considerando o conhecimento, a experiência e 0 significado que 0 aluno traz à sala de aula, seu potencial cognitivo, sua capacidade e interesse, seu procedimento de pensar, seu modo de trabalhar. Nesse sentido, 0 conhecimento de mundo ou o conhecimento prévio do aluno tem de ser respeitado e ampliado. (LIBÂNEO, 1998, p. 29).

A relação professor-aluno deve possibilitar experiências transformadoras no contexto de aprendizagem. Por muito tempo, a prática educativa esteve centrada no profissional, e não no aluno. 0 professor era aquele transmitia os conteúdos sem reflexão ou mesmo sem indagação por parte do seu público-alvo. Hoje, com tantas transformações educativas, o aluno passou a ser protagonista de sua aprendizagem, e o professor faz a mediação desse processo. 
P4, por sua vez, afirma que cabe ao professor: "Estimular a criança a desenvolver seus aspectos físicos e cognitivos e sua psicomotricidade". Sobre esse mesmo tópico, P5 afirmou: "Capacitar o seu aluno para a vida e o mundo em que vivemos, de acordo com a nossa realidade. Desenvolver seu raciocínio lógico, coordenação motora ampla e fina e seu convívio com o mundo". Nessas respostas, as professoras frisaram a importância de desenvolver os aspectos físicos e cognitivos do alunado e capacitá-Io para a vida e para o mundo. Percebemos que, nas falas dessas professoras, há um entendimento de que o professor é essencial para a formação dos sujeitos na Educação Infantil, contribuindo para o desenvolvimento dos alunos. A LDB, em seu art. 31, ressalta que: "Na Educação Infantil a avaliação far-se-á mediante acompanhamento e registro de desenvolvimento, sem 0 objetivo de promoção, mesmo para o acesso ao Ensino Fundamental". Os arts. 29 e 31 deixam claro que o papel do professor ou da Educação Infantil não é uma preparação para a série seguinte, mas 0 desenvolvimento da criança em seus aspectos físicos, psicológicos, intelectuais e sociais.

Em relação ao eixo 3, que diz respeito às contribuições das temáticas metodológicas dos encontros de formação continuada e os registros de observações, em primeiro lugar é importante ressaltar que a formação continuada tem sido apontada como um dos caminhos para uma melhor qualidade do ensino, cabendo ao professor o compromisso de estar sempre se atualizando, estudando, pesquisando e refletindo sobre sua prática. Um profissional consciente sabe que seus conhecimentos são construídos a cada processo educativo e exige intervenções por sua parte. É 0 que afirma Freire (1991, p. 58) neste trecho: "Ninguém nasce educador ou marcado para ser educador. A gente se forma, como educador, permanentemente, na prática e na reflexão da prática". Para 0 educador pernambucano, a formação permanente permite a obtenção de uma maturidade, que se reflete na prática.

De forma unânime, as professoras afirmaram que os encontros formativos contribuíram para as suas práticas pedagógicas. P1 afirmou: "Como todos os encontros são de muita importância e contribuição com a nossa prática pedagógica em sala de aula, quem ganha com isso são nossos alunos". Uma outra pergunta que também foi respondida pelas participantes foi a seguinte: que Matemática podemos ensinar para os alunos? Para esta pergunta, obtemos esta resposta de P2:

0 curso contribui como um guia, pois hoje enxergo a Matemática na Educação Infantil de uma forma diferente. Hoje eu percebo que não preciso usar o nome 'Matemática' e muito menos fazer meu aluno escrever dez vezes um número colorindo um pontiIhado para dizer que ele aprendeu, pois a Matemática está em tudo. Os alunos usam a Matemática nas suas vivências, brincadeiras, histórias, entre outras situações.

Percebemos que, nessa resposta, a professora expressa uma valorização do pensamento crítico, conforme preconizado pelo RCNEl para o ensino da Matemática.

A temática das Metodologias Ativas (2..$^{\circ}$ encontro) trouxe como contribuição para as professoras uma nova forma de ensinar, na qual o conhecimento do aluno adquire protagonismo, firmando-se, assim, como uma oposição ao chamado ensino "tradicional" para a prática pedagógica em sala de aula. Além disso, nessas metodologias, o professor é o mediador da aprendizagem. As cursistas entenderam que 0 aluno é 0 centro do processo de aprendizagem e da construção do conhecimento. P4 afirmou: "Com esses estudos, fica cada dia mais claro que temos que abandonar os materiais impressos e valorizar o conhecimento do aluno, porque o aluno aprende mais assim. Ele não vai ficar só escrevendo no caderno, e sim desenvolvendo atividades em que terão mais resultados". P5, 
por sua vez, comentou: "Formações como essa são necessárias, pois vêm discutir a prática da sala de aula, e esse é o anseio da maioria dos professores".

Sobre 0 encontro do Material Dourado (3. ${ }^{0}$ encontro), as professoras expressaram-se de forma positiva. Elas vêm 0 uso de tal material como uma forma inovadora de ensinar. Vejamos as falas a esse respeito: "Gostei da metodologia e pretendo usar em sala e tornar minhas aulas mais atrativas" (P8); "Eu já tinha trabalhado no ensino fundamental, mas, na Educação Infantil, não" (P9); "0 encontro contribuiu para o esclarecimento de dúvidas em relação ao Material Dourado na Educação Infantil. Este pode ser trabalhado de maneira lúdica, fazendo com que os alunos aprendam e desenvolvam muitas habilidades simplesmente com esse material" (P10). Acreditamos, então, que o encontro sobre o Material Dourado possibilitou mais uma ferramenta de trabalho durante os processos de ensino e de aprendizagem na Educação Infantil, o que pode ser um valioso instrumento de mudanças nas atividades de sala de aula para 0 ensino da Matemática.

Sobre 0 encontro da Produção de Cartoons na Educação Infantil (4. ${ }^{\circ}$ encontro), as professoras também viram essa atividade como algo inovador. P13 frisou: "participar dessa formação foi tudo novidade para mim, aprendi tantas coisas, até conhecer funções do computador que não sabia usar". Percebemos, em falas como essas, que o uso das tecnologias é um grande desafio para as professoras, mas elas estão abertas à aprendizagem. De fato, as professoras mostraram-se bastante interessadas em aprender novas atividades mediadas por ferramentas como 0 computador. 0 uso de cartoons foi visto, nos relatos das professoras, como um meio de levar a criatividade para a sala de aula.

Em relação à temática Matemática e Literatura ( $6{ }^{\circ}$ encontro), apresentamos para as participantes atividades envolvendo as noções matemáticas, as quais são defendidas por Lorenzato (2011). Foram abordados os sete passos mentais básicos para a aprendizagem matemática e a organização dos três blocos de conteúdos matemáticos, que também são defendidos pelo RCNEl (1998). Estas ações foram trabalhadas com as professoras de forma lúdica, envolvendo brincadeiras dirigidas e a resolução de problemas. Para P4, "temos muito que aprender e infelizmente não temos uma pessoa para orientar. [...] Eu sou aberta para aprender, pois a Educação Infantil está sendo um desafio na minha vida".

A temática da Caixa da Matemática ( $7 .^{\circ}$ encontro) contribuiu muito para a aquisição de competências para 0 trabalho com contagem, conceitos e relação e sequência numérica e para as situações-problema no campo aditivo. As participantes fizeram um dado numérico de tamanhos diferentes com garrafas pet. A criança pode brincar, sentar-se, jogar e manusear livremente esse material, sem a preocupação de rasgá-lo ou quebrá-lo.

Sabe-se que a Educação Infantil é o alicerce para uma vida estabilizada futuramente. Trata-se de um período de muito conhecimento da criança, que, bem desenvolvido em suas estruturas, garantirá o sucesso em aspectos como 0 social, o afetivo, cognitivo e o motor. Se não for bem desenvolvido, esse estágio comprometerá o desenvolvimento global ou integral da criança. Foi precisamente isso 0 que afirmou o palestrante do curso sobre psicomotricidade ( $8 .^{\circ}$ encontro).

Podemos perceber, portanto, que, ao longo dos oito encontros, as angústias relatadas pelas professoras foram aos poucos sendo respondidas. As perguntas "0 que ensinar na Pré-Escola?" e "até onde o professor pode ensinar?" foram feitas aos palestrantes do curso da BNCC ( $5 .^{\circ}$ encontro) e da Psicomotricidade ( $8 .^{\circ}$ encontro). Os palestrantes explanaram sobre a implementação da BNCC na Educação Infantil e expuseram que esse documento, junto a DRC-MT, iria sanar muitas dúvidas das professoras. Além disso, explicaram também sobre as dez competências e como essas poderiam ser trabalhadas na Educação Infantil. 


\section{CONSIDERAÇOES FINAIS}

0 objetivo desta investigação foi discutir a respeito da experiência de formação continuada no ensino de Matemática para professores da Educação Infantil do município de Matupá. Para isso, procuramos compreender como a formação continuada pode contribuir para a prática pedagógica do professor de Educação Infantil, no que se refere ao ensino de Matemática. Estabelecemos, ainda, objetivos específicos, quais foram: contribuir com uma experiência de formação continuada no ensino de Matemática para professores da Educação Infantil de quatro e cinco anos no município de Matupá; refletir com os professores da escola pesquisada sobre os desafios que eles enfrentam na sala de aula em relação ao ensino da Matemática na Educação Infantil; e identificar quais as contribuições que esta formação continuada pôde proporcionar aos docentes.

Sendo assim, foram realizados oito encontros de formação continuada voltados para 0 ensino da Matemática na Educação Infantil. Com base nos relatos das professoras participantes desses encontros, percebemos que a formação foi vista como algo benéfico, caracterizando-se como uma ação que contribuiu efetivamente para a melhoria da atuação da prática pedagógica das professoras da Educação Infantil. A pesquisa também revelou que os encontros de formação proporcionaram um elo importante entre a teoria e a prática pedagógica, possibilitando, entre as participantes, trocas de experiências e vivências no cotidiano do ambiente escolar. A partir de nossas experiências nesses encontros formativos, identificamos que é preciso provocar nas professoras dessa modalidade de educação a sensibilização para a importância de se propor às crianças atividades desafiadoras, abrindo espaços de reflexão da própria prática do professor.

Apontamos que, perante isso, é preciso repensar o ensino de Matemática na Educação Infantil, principalmente os conceitos matemáticos que representam a aprendizagem da criança. Há muitos aspectos que instigam os alunos e que são necessários ao trabalho na Educação Infantil. Nesse sentido, cresce ainda mais a importância de se estudar e aprimorar o conhecimento sobre essa fase na vida da criança. Ressaltamos, então, que o compromisso do professor, da escola e do município com 0 ensino e a aprendizagem dos sujeitos deva se dar por meio das formações nessa areá aos professores dessa modalidade de ensino.

Além disso, verifica-se que a Base Nacional Comum Curricular, poderá contruibuir nesta areá de conhecimento matemático, por meio do planejamento docente, utilizando-se das experiências e das habilidades das crianças para que possam ampliar as noções matemáticas, considerando a realidade e os fatos cotidianos.

\section{REFERÊNCIAS}

BRASIL. Lei n. ${ }^{0}$ 9.394, de 20 de dezembro de 1996. Estabelece as diretrizes e bases da Educação nacional. Diário Oficial [da] República Federativa do Brasil, Poder Legislativo, Brasília, DF, 23 dez. 1996. p. 27833. Disponível em: https://bit.ly/1RMCEoz. Acesso em: 23 maio 2019.

BRASIL. Ministério da Educação. Referencial curricular nacional para a Educação Infantil / Ministério da Educação e do Desporto, Secretaria de Educação Fundamental. Brasília, DF: MEC/SEF, 1998.

BRASIL. Ministério da Educação. Referenciais para a Formação de Professores. Brasília, DF: Secretaria de Educação Fundamental, 2002. Disponível em: https://bit.ly/2yfYrFN. Acesso em: 25 nov. 2018. 
BRASIL. Ministério da Educação. Diretrizes curriculares nacionais para a Educação Infantil. Brasília, DF: MEC/SEB, 2010.

BRASIL. Ministério da Educação. Base Nacional Comum Curricular (BNCC). Brasília: MEC, 2017. Disponível em: http:basenacionalcomum.mec.gov.br/. Acesso em: 10 maio 2018.

BOGDAN, R.; BIKLEN, S. Investigação qualitativa em Educação: uma introdução à teoria e aos métodos. Porto: Porto Ed., 1994.

FREIRE, P. A Educação na Cidade. São Paulo: Cortez, 1991.

FREIRE, P. Pedagogia da Esperança. Um reencontro com a Pedagogia do Oprimido. Rio de Janeiro: Paz e Terra, 2002.

KRAMER, S. As Crianças de 0 a 6 Anos nas Políticas Educacionais no Brasil: Educação Infantil e/é Fundamental. Revista Educação e Sociedade, Campinas, v. 27, n. 96, p. 797-818, out. 2006.

KRAMER, S. Formação de profissionais de educação infantil: questões e tensões. In: MACHADO, M. L. de A. (Org.). Encontros e desencontros em educação infantil. São Paulo: Cortez, 2002.

LIBÂNEO, J. C. Adeus professor, adeus professora? Novas exigências educacionais e profissão docente. São Paulo: Cortez, 1998.

LORENZATO, S. Laboratório de Ensino de Matemática na Formação de Professores. Coleção Formação de Professores. Campinas: Autores Associados, 2006.

LORENZATO, S. Educação Infantil e percepção Matemática. 3. ed. rev. Campinas, SP: Autores Associados, 2011.

MATO GROSSO. Documento de Referência Curricular para o Mato Grosso. Cuiabá: Secretaria de Estado de Educação, Cadernos de Educação Infantil, 2018.

MELLO, M. T. L. de. Programas oficiais para a formação de professores. In: Educação e Sociedade, n. ${ }^{0}$ 68. Campinas: Cedes, 1999.

MINAYO, M. C. S. 0 desafio do conhecimento: pesquisa qualitativa em saúde. 7. ed. Rio de Janeiro: Hucitec-Abrasco, 2000.

NÓVOA, A. A profissão e a prática na formação continuada de professores. $4 .^{\circ}$ Encontro Nacional das Licenciaturas (Enalic), Universidade Federal do Triângulo Mineiro, Uberaba, Minas Gerais, 2013. Anais... Disponível em: https://bit. ly/2ZBOscC. Acesso em: 02 maio 2018.

NÓVOA, A. Formação contínua de professores: realidade e perspectivas. Portugal: Universidade de Aveiro, 1991.

NÓVOA, A. Formação de professores e profissão docente. In: NÓVOA, A. (Org.). Os professores e a sua formação. 2. ed. Lisboa: Dom Quixote, 1995.

NÓVOA, A. Os professores e sua formação. Lisboa: Dom Quixote, 1992.

NÓVOA, A. Os novos pensadores da educação. Revista Nova Escola, edição n. ${ }^{0}$ 154, agosto/2002, p. 23. 
PERRENOUD, P. Dez novas competências para ensinar. Porto Alegre: Artmed, 2000.

SEVERINO, A. J. Metodologia do Trabalho Científico. São Paulo: Cortez, 2007.

SMOLE, K. S.; DINIZ, M. I.; CÂNDIDO, P. Resolução de Problemas. Vol. 2. Col. Matemática de 0 a 6. Porto Alegre: Ed. Artmed, 2000.

TANCREDI, R. M. S. P. A matemática na Educação Infantil: algumas ideias. In: PIROLA, N. A.; AMAR0, F. de 0. S. T. (Org.). Pedagogia Cidadã: Cadernos de Formação: Educação Matemática. Unesp: Pró-Reitoria de Graduação, 2004.

THIOLLENT, M. Metodologia da pesquisa-ação. São Paulo: Cortez, 2005.

RECEBIDO EM: 01 abr. 2020

CONCLUÍDO EM: 30 set. 2020 